

RESEARCH ARTICLE

\title{
An Experimental Study on Dynamic Model Groove Under Shock Excitation
}

\author{
Changmin Yang ${ }^{1, *}$, Tongfei Hou ${ }^{1}$, Bing $\mathrm{Cui}^{2}$ and Jiaqi Lou ${ }^{1}$ \\ ${ }^{1}$ School of Architecture and Engineering, Hebei University, Baoding, Hebei 071002, China \\ ${ }^{2}$ Shanghai Zhongliang Real Estate Group Co. LTD, Shanghai 200000, China
}

\begin{abstract}
:
Introduction:

Variation laws of dynamic response and settlement deformation at different depths of soil roadbed were investigated and summarized in this study through a simulation test with a dynamic model groove in soft clay foundation of low road embankment.

Materials and Methods:

In this test, the traffic load was simulated by single-point and double-point shock excitation. Besides, loading frequency, intensity and duration were adjusted by a single variable control method. Research results show that peak values of soil pressure and pore water pressure decrease with the increase of buried depth, but they are unrelated to loading intensity and frequency.

\section{Conclusion:}

Nevertheless, settlement deformation does not increase linearly with the increase of frequency or time difference. The accumulative settlement at a depth varies as the loading time increases.
\end{abstract}

Keywords: Soft clay foundation, Low embankment, Traffic load, Dynamic response, Shock excitation, Accumulative settlement.

\begin{tabular}{|l|l|l|l|}
\hline Article History & Received: August 01, 2019 & Revised: September 23, 2019 & Accepted: October 10, 2019
\end{tabular}

\section{INTRODUCTION}

Many scholars have carried out experimental studies on dynamic response and settlement deformation of soil roadbed under traffic loads [1]. In dynamic analysis, Huang [2] simulated roadbed as a viscoelastic half-space and explored dynamic responses of vehicles under different forms of loads and travelling speeds. Jia et al. [3] constructed a finite element model based on the structure and characteristics of a highway roadbed and pavement with four lanes and applied traffic loads onto the model based on the dynamic analysis theory of vehicles, through which the dynamic response parameters of roadbed were collected. Zha et al. [4] deduced the coupling equation of motion by constructing a dynamic analysis coupling mechanics model of the roadbed and studied dynamic response laws by combining different working conditions. In the model test, Liu et al. [5] simulated traffic loads through a hydraulic cyclic loading system and performed an indoor model test on deformation characteristics of saturated clay foundation which pointed out the variation law of settlement

\footnotetext{
* Address correspondence to this author at School of Architecture and Engineering, Hebei University, Baoding, Hebei 071002, China;

Tel: 13383123086; E-mail: changmyang@126.com
}

and pore water pressure with a number of loading cycles and loading frequency. Wu et al. [6] carried out a horizontal static load model test on embedded single-pile base in saturated soft clay and sandy clay foundation by using a self-made horizontal loading device, which disclosed the horizontal bearing capacity and deformation characteristics of the single-pile base. Huazhong et al. [7] implemented a simulation test of low embankment under traffic loads by using the self-designed and improved consolidometer, and concluded the variation curve of roadbed settlement at different cyclic loading ratios. They further deduced the relation expression between a number of loading cycles and accumulative strain.

Based on the above analysis, Chinese and foreign scholars have made great contributions to roadbed under traffic loads as well as dynamic response and settlement of pavement, such as field tests and numerical simulation. They have gained many valuable conclusions. This has become a key research direction in China and foreign countries. However, there are few studies concerning soft clay foundation under the low embankment. Combining with existing research status, an indoor simulation test was carried out. Based on the constructed model, variations of dynamic responses and uneven settlement of soft clay 
foundation of low embankment under traffic loads were summarized. Research conclusions can provide references to reduce the uneven settlement of the foundation.

\section{MATERIALS AND METHODS}

\subsection{Indoor Model}

\subsubsection{Test Equipment Overview}

The whole experimental apparatus composed of model groove, loading system and measurement system is shown in Figs. (1 and 2). The hydraulic jack which is controlled independently by a computer was used as the loading system and the form, frequency and strength of applied loads could be adjusted by a computer. The measurement system was divided into externally measuring equipment and monitoring elements on the exciter. Test results were accepted by the embedded computer. The reading instrument and measuring equipment of settlement are shown in Figs. (3 and 4). The net space size of the model groove which was zoomed proportionally was $2 \mathrm{~m} \times 1 \mathrm{~m} \times 0.8 \mathrm{~m}$. Two pieces of $0.5 \mathrm{~cm}$ thick steel plates were fixed at two sides of the model groove. Steel plates could be set horizontally according to practical needs.

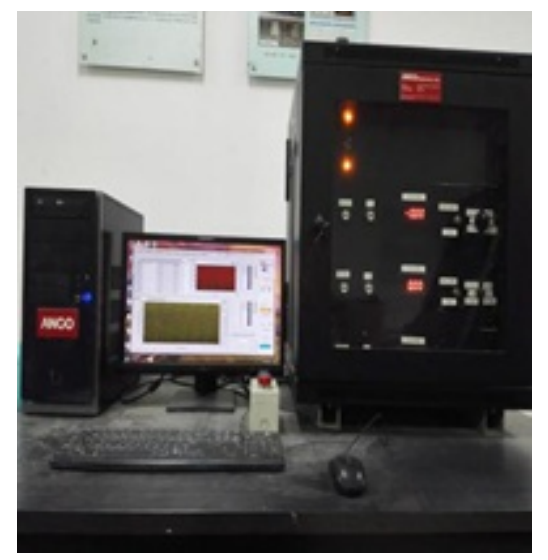

Fig. (1). Control device.

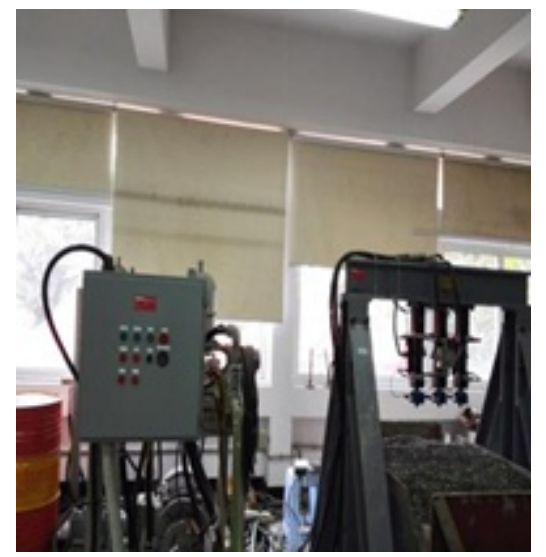

Fig. (2). Loading device.

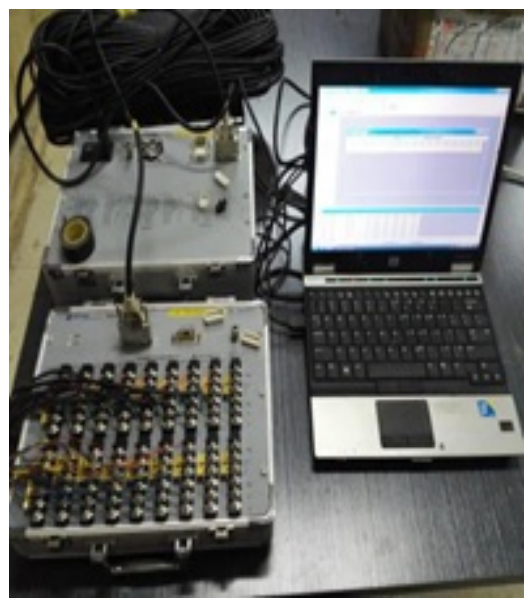

Fig. (3). Monitoring equipment.

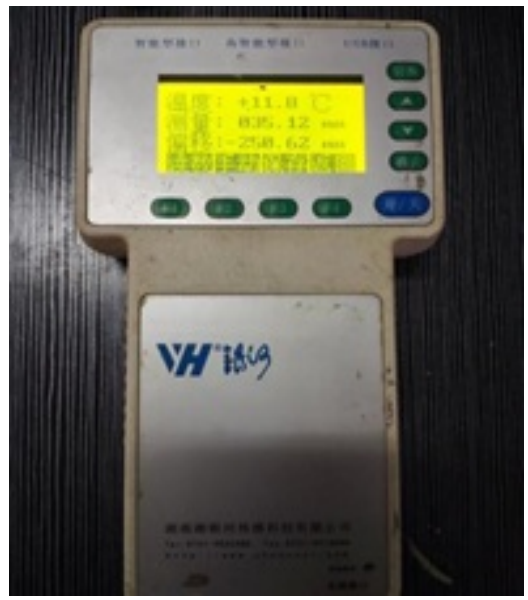

Fig. (4). Universal reader.

\subsubsection{Model Design and Measurement Point Layout}

According to practical engineering and the principle of the ratio of similitude, a model was manufactured according to the proportion of 1:10. The thicknesses of different layers in the model are shown in Figs. (5 and $\mathbf{6}$ ).

The traffic load

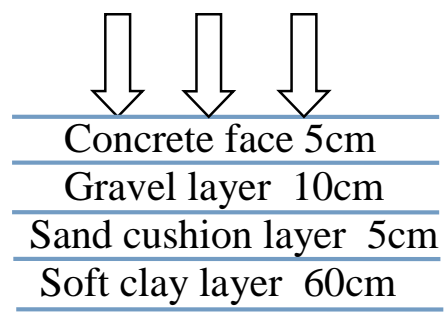

Fig. (5). Road hierarchy diagram. 


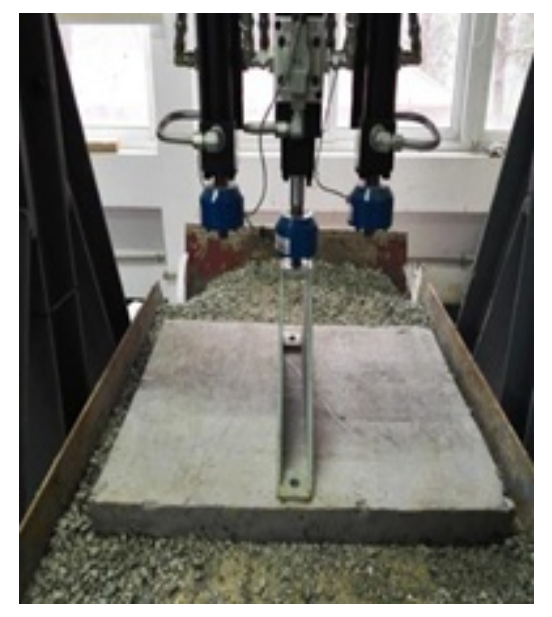

Fig. (6). Model slot.

\subsubsection{Test Component Burying}

Limited by data availability and size of model groove, three pore water pressure gauges and earth pressure gauges were set on the middle exciter in this experiment, which was denoted as $1 \#, 2 \#$ and $3 \#$ from up to bottom. These three gauges were $20 \mathrm{~cm}, 40 \mathrm{~cm}$ and $60 \mathrm{~cm}$ away from the soil surface Fig (7-9).

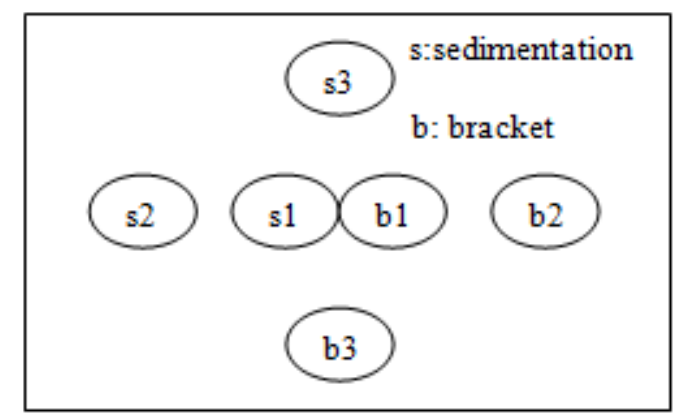

Fig. (7). Test element plan.



Fig. (8). Single point sedimentation meter.



Fig. (9). Test component profile.

\subsubsection{Dynamic Loading Scheme}

In this experiment, an impact load model was applied as the traffic load model $[8,9]$. Figs. (10 and 11) show the single and double point excitation curves.

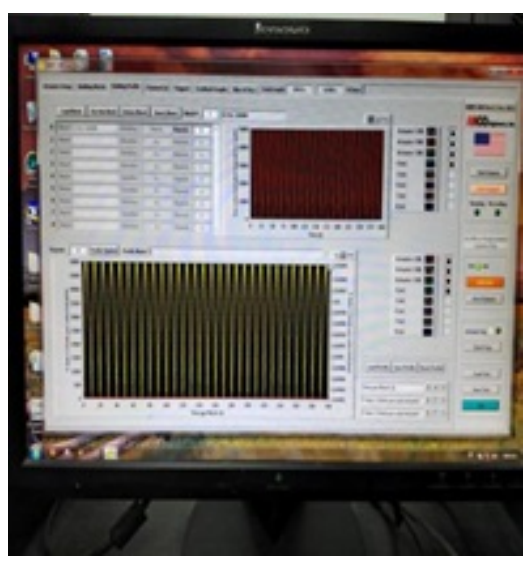

Fig. (10). Single point excitation curve.

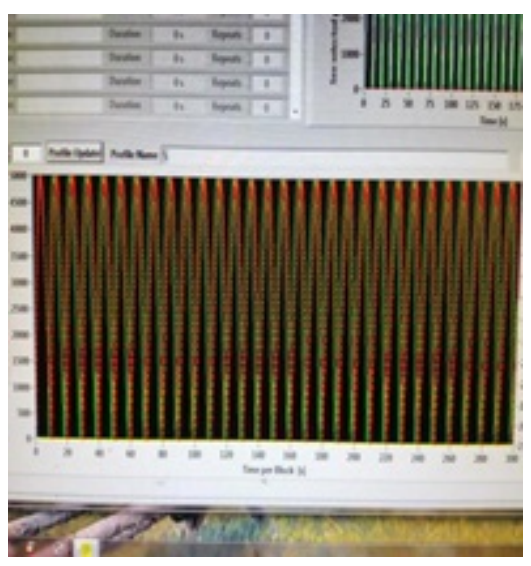

Fig. (11). Double point excitation curve. 
Single-point and double-point shock excitation was applied in the process of loading. A single variable control method was used in this experiment [10]. Firstly, loading frequency, loading intensity and loading duration of single-point excitation were set $0.1 \mathrm{~Hz}, 1 \mathrm{~Hz}$ and $5 \mathrm{~Hz}, 3 \mathrm{KN}, 5 \mathrm{KN}$ and $7.5 \mathrm{KN}$ as well as 300s, 600s and 900s, respectively. Then, doublepoint shock excitation was considered by changing time difference and frequency. Influencing laws of loading parameters on dynamic characteristics and settlement deformation of soft clay foundation under low embankment were summarized. Limited by the length of this article, only dynamic characteristics and settlement deformation of doublepoint excitation under specific parameters were discussed only.

\section{RESULTS AND DISCUSSION}

\subsection{Test Result And Analysis Under Dymanic Load}

\subsubsection{Analysis of Single Point Excitation Test Results}

\subsubsection{Analysis of Soil Pressure Results}

Variation curves of soil pressure with frequency and buried depth of the middle soil pressure gauge are shown in Fig. (12).
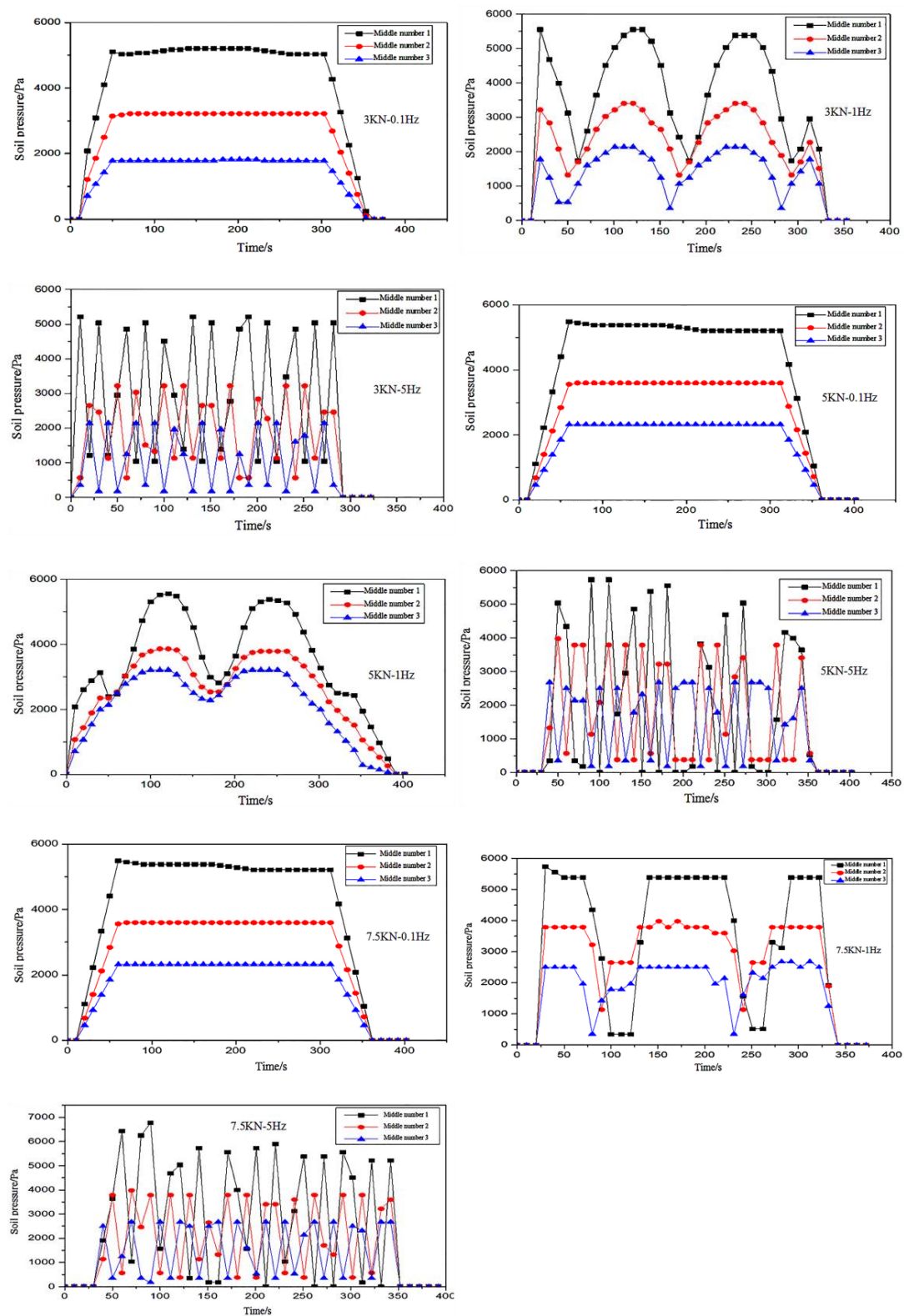

Fig. (12). Variation curves of soil pressure. 

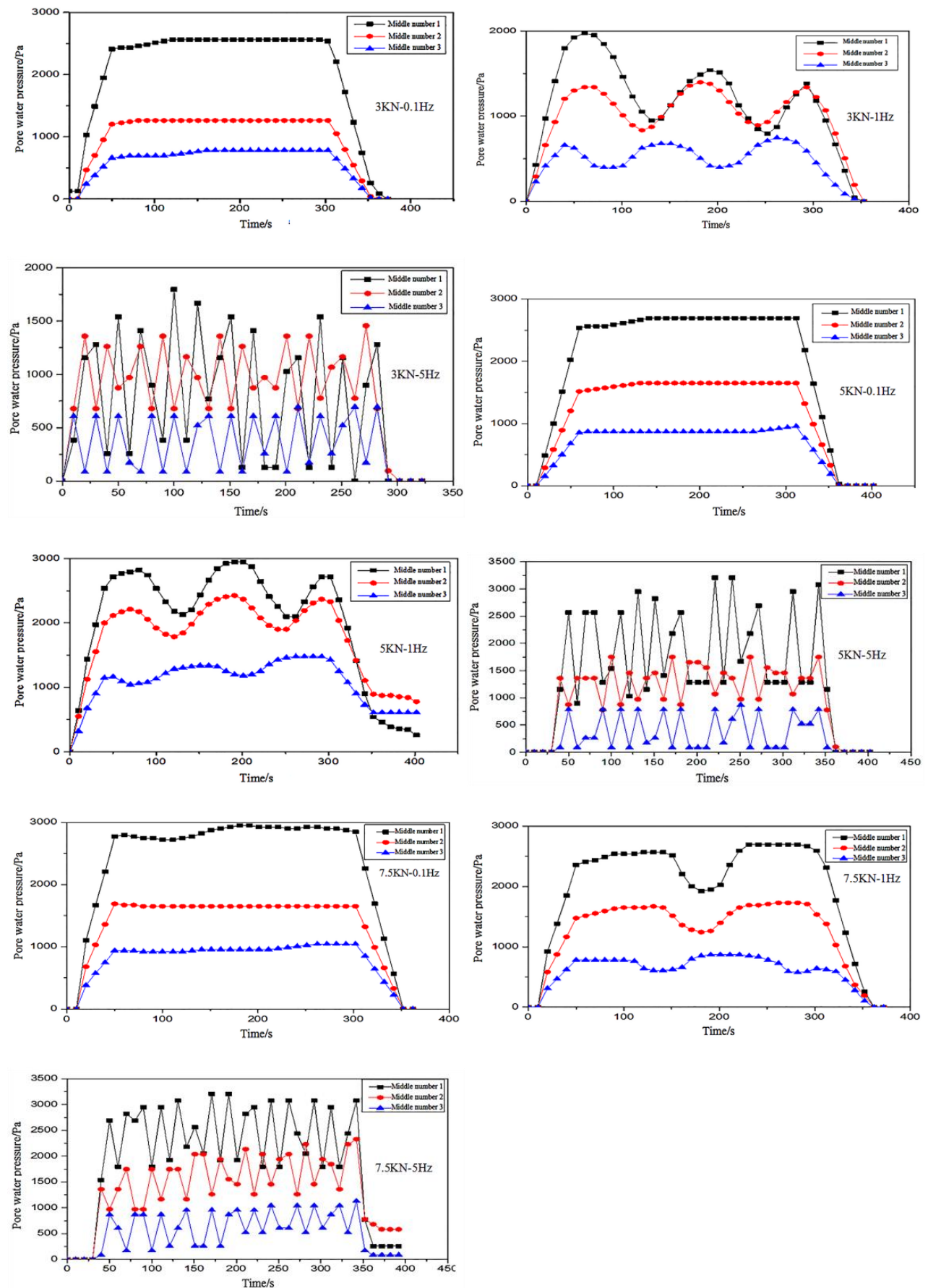

Fig. (13). Variation of pore water pressure.

It can be seen from a variation trend of soil pressure curve that given a fixed loading intensity, the soil pressure curve fluctuates more violently with the increase of loading frequency. Soil pressure on the top layer is the maximum no matter how loading frequency changes. According to a longitudinal comparison of the maximum soil pressure on the top layer is positively related to loading intensity when the loading frequency is fixed. On the contrary, soil pressure in the bottom two layers increases slightly. Loading intensity is an important influencing factor that changes the soil pressure peak. 


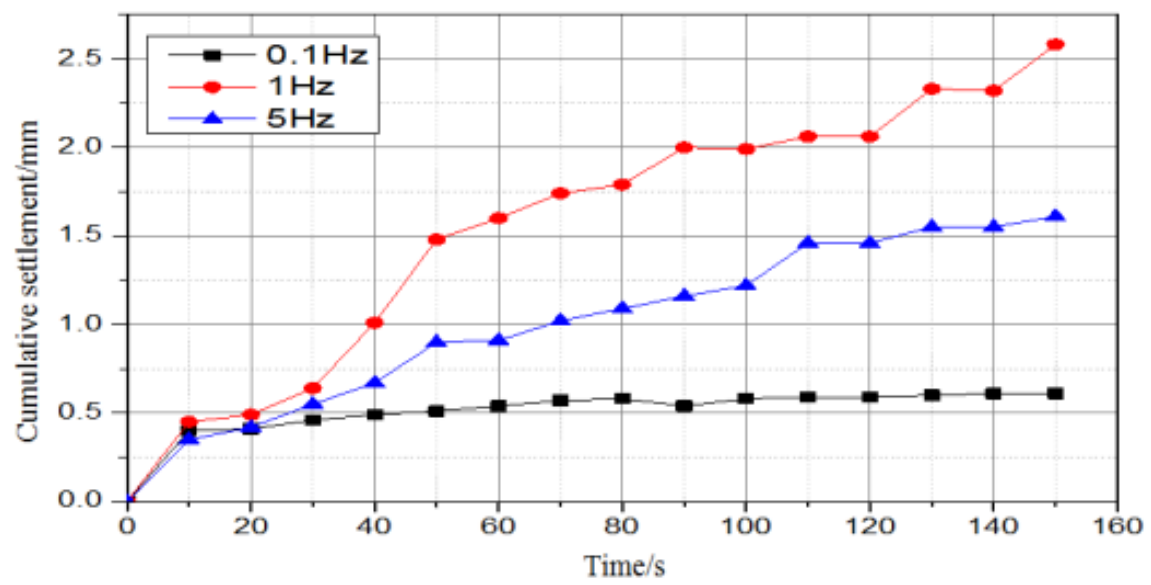

Fig. (14). Accumulative settlement under different loading frequencies when loading intensity is $5000 \mathrm{~N}$.
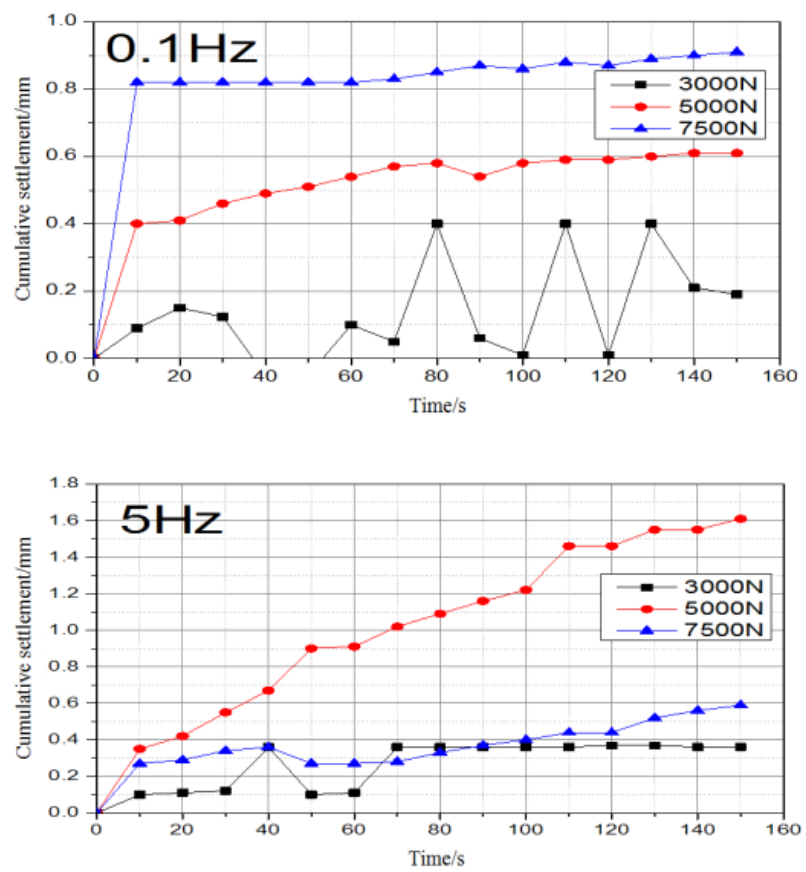

Fig. (15). Accumulative settlement curve in the middle position.

\subsubsection{Analysis of Pore Water Pressure Results}

It can be seen from Fig. (13) that pore pressure attenuates gradually with the increase of buried depth, which agrees with a variation trend of soil pressure. When loading frequency increases from a low level, a variation trend of pore pressure intensifies gradually. It can be found by comparing three diagrams at $1 \mathrm{~Hz}$ that pore pressure presents a hysteresis in single-point shock excitation.

\subsubsection{Sedimentation Analysis}

It can be seen from Figs. (14 and 15) that the maximum accumulative settlement is achieved when the loading frequency is $1 \mathrm{~Hz}$ and the minimum accumulative settlement is achieved at $0.1 \mathrm{~Hz}$ and $5 \mathrm{~Hz}$. This reflects that the accumulative settlement reaches the maximum at certain values of loading

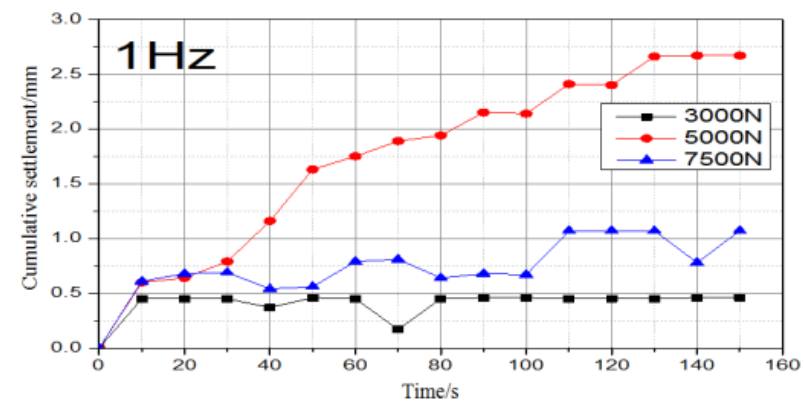

frequency and loading intensity. The author believes that this shall be related to the inherent frequency of foundation and external loading frequency. Resonance occurs when loading frequency is close to the inherent frequency of the foundation. Therefore, the produced accumulative settlement is relatively high [11].

\subsubsection{Analysis of Double-point Excitation Test Results}

\subsubsection{Analysis of Soil Pressure and Hole Pressure}

Variation curves of soil pressure and pore pressure in middle gauges at different buried depths under double-point shock excitation are shown in Fig. (16).

It can be seen from Fig. (16) that when the time difference is $0.3 \mathrm{~s}$, soil pressure and pore pressure change slightly. When 
the time difference is $0.5 \mathrm{~s}$, soil pressure and pore pressure fluctuate in a small range, but the fluctuation frequency increases gradually. When the time difference is $0.8 \mathrm{~s}$, the fluctuation range begins to extend. The loading frequency of $0.8 \mathrm{~s}$ is close to the inherent frequency at single-point shock excitation, the peak is higher than that under single-point shock excitation.

\subsubsection{Settlement Test Results Analvsis}

Accumulative settlement curves of the middle settlement gauge are shown in Figs. (17 and 18). When the loading
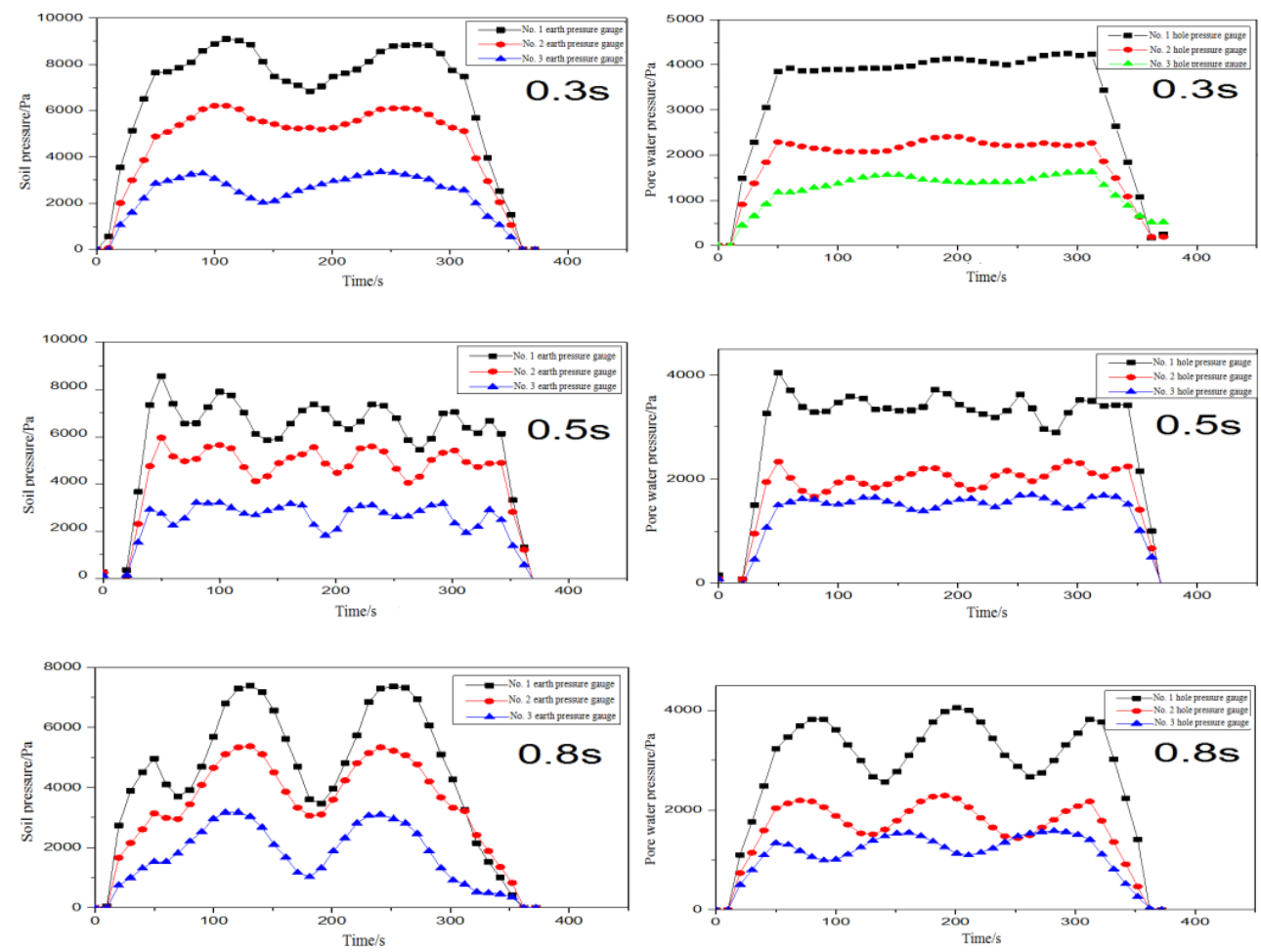

Fig. (16). Variation curves of soil pressure and pore pressure under different time difference.

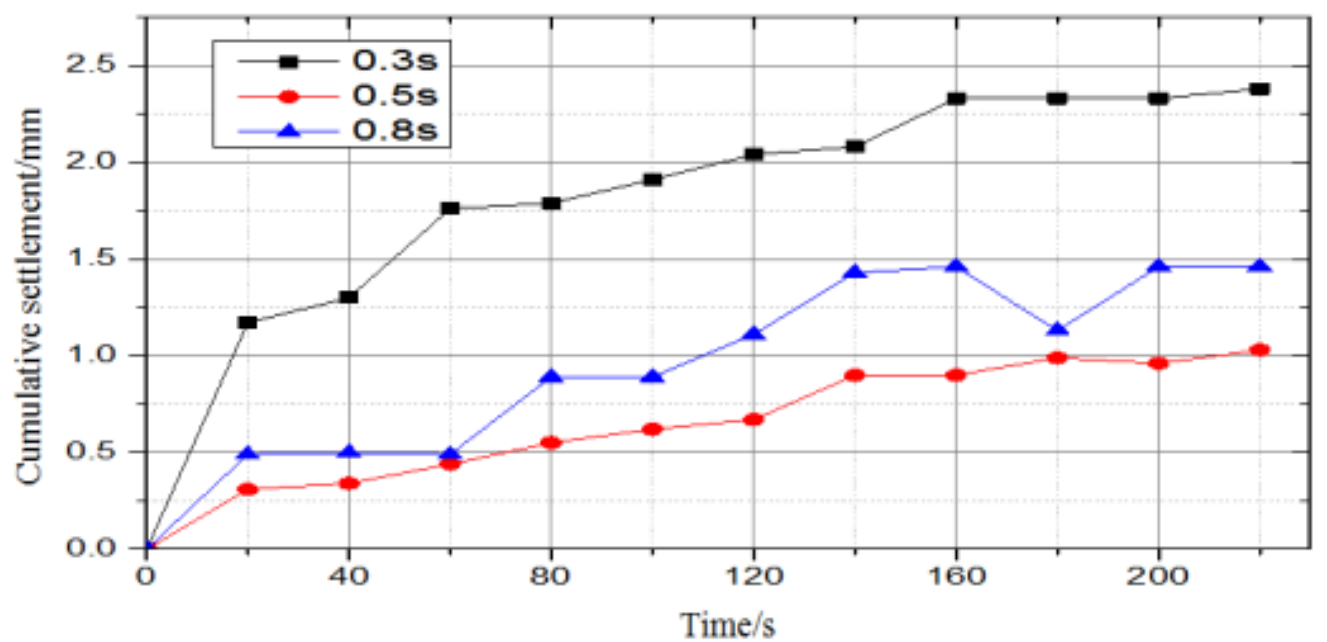

Fig. (17). Accumulative settlement curve in double-point shock excitation under $0.1 \mathrm{~Hz}$. 


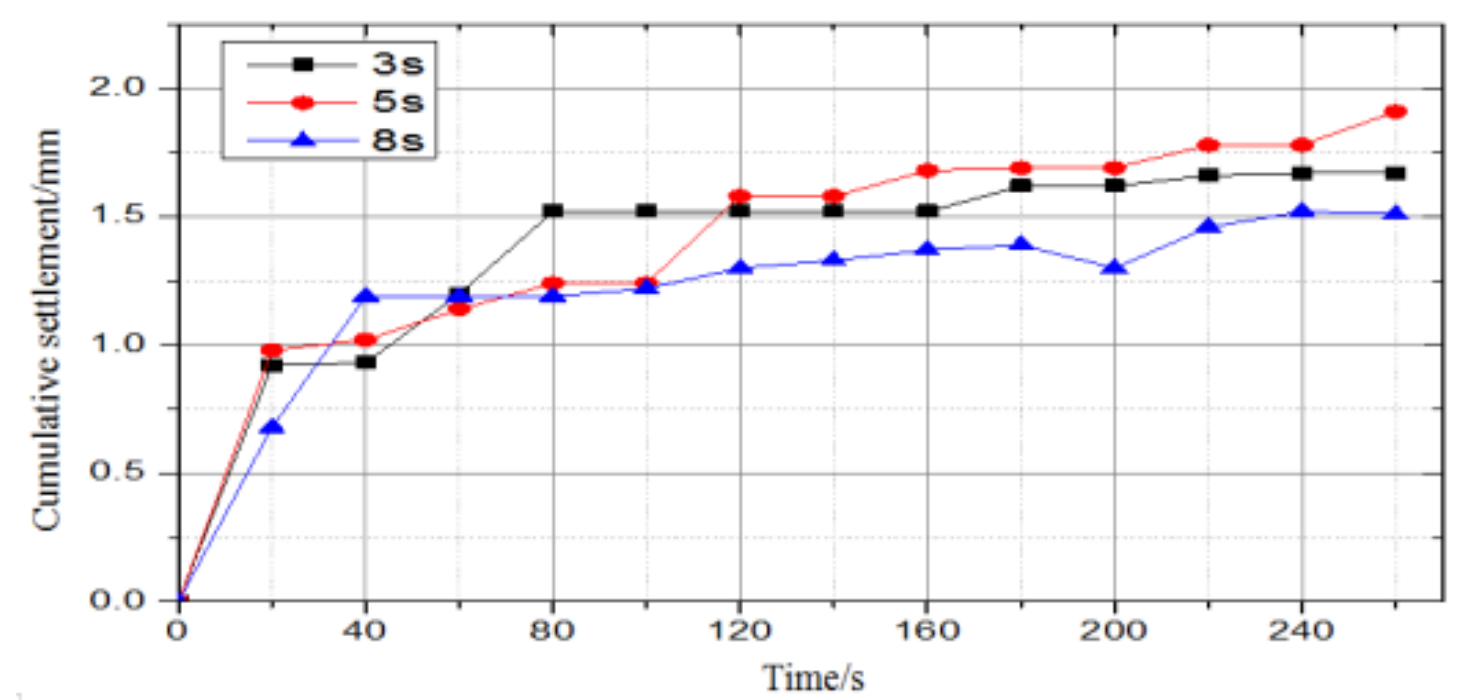

Fig. (18). Accumulative settlement curve in double-point shock excitation under $1 \mathrm{~Hz}$.

\section{CONCLUSION}

In the model test, variation laws of soil pressure, pore water pressure and settlement of a soft clay foundation of a low embankment under traffic loads due to influences of loading intensity, frequency and time difference were concluded. Two conclusions could be drawn:

(1) Under single-point shock excitation, if loading intensity and loading frequency are fixed, the maximum soil pressure and pore pressure attenuate gradually with the increase of buried depth. Compared with soil pressure, pore pressure attenuates more. Therefore, it is very necessary to restrict the speed of a motor vehicle on the road with a low embankment and soft clay foundation. At low loading frequency, the accumulative settlement is positively related to loading intensity. When loads and loading frequency are at special values, the accumulative settlement reaches the peak with the increase of loading frequency.

(2) Under double-point shock excitation, fluctuation of maximum pore pressure and soil pressure with the increase of buried depth is more violent than that under single-point shock excitation. Soil pressure and pore pressure are affected by time difference significantly. When there are many vehicles passing through a position continuously, the accumulative settlement is relatively high. Given a fixed loading frequency, the accumulative settlement is increased slightly with the increase of time difference. Loading intensity influences the final accumulative settlement significantly.

\section{CONSENT FOR PUBLICATION}

Not applicable.

\section{AVAILABILITY OF DATA AND MATERIALS}

The experimental data in this paper is obtained by using the indoor dynamic model test equipment independently development by Wenzhou University in China.

\section{FUNDING}

None.

\section{CONFLICT OF INTEREST}

The authors declare no conflict of interest, financial or otherwise.

\section{ACKNOWLEDGEMENTS}

The authors would like to acknowledge Professor Wang Jun and Professor Ding Guangya for their help and support during the research at Wenzhou University in China.

\section{REFERENCES}

[1] Z. Junming, L. Songyu, and S. Minglei, "Experimental study on dynamic characteristics of low embankment under traffic load", $J$. Southeast University, vol. 37, no. 5, pp. 921-925, 2007. [Natural Science Edition].

[2] H.H. Hung, and Y.B. Yang, "“Elastic wave in vicco-elastic half-space generated by various vehicle loads", Soil Dynam", Earthquake Eng, vol. 21 , p. 117, 2001.

[3] W. Jia, Z. Jiasheng, and M. Fei, "Study on dynamic response of highway subgrade under traffic Loading", Subgrade Eng, vol. 2, pp. 7-10, 2013.

[4] Z. Wenhua, and H. Baoning, "Dynamic response of low embankment subgrade under traffic load", J. Jiangsu University, vol. 29, no. 3, pp. 264-268, 2008. [Natural Science Edition].

[5] L. Shengqun, and Z. Xiao, "Experimental study on settlement model of soft soil foundation under traffic load", Subgrade Eng, vol. 6, pp. 28-29, 2008

[6] W. Jinbiao, L. Yang, and Z. Jianjing, "Model test study on horizontal load of single pile foundation in saturated soft clay ground", Subgrade Eng, vol. 5, pp. 43-47, 2017.

[7] J. Huazhong, L. Guowei, and Y. Xiangjuan, "Laboratory experimental study and settlement calculation of low embankment soft foundation under traffic loading", Highway, vol. 10, pp. 59-62, 2006.

[8] Y. Li, "Research on deformation characteristics of saturated silt subgrade", M.S. Thesis, Henan University of Technology, 2010.

[9] C. Yong, "Numerical simulation of the influence of traffic loads on the subgrade of expressway with low embankment", M.S. Thesis, Hohai University, 2006.

[10] H. Wei, C. Jian, K. Wenhui, Z. Yu, and Q. Yuefeng, "Experimental study on pore pressure test of saturated soft clay under the action of bidirectional excitation cyclic loading and vibration frequency", Chinese J. Geotech. Eng, vol. 39, pp. 71-74, 2017.

[11] B. Zhenning, J. Wei, and L. Jianwen, "Dynamic response analysis of 
layered soil-track coupling system under moving harmonic loads", $J$. Vibrat. Shock, vol. 35, no. 12, pp. 61-70, 2016.
[12] S. Bo, "Study on dynamic response and long-term settlement of soft soil foundation under traffic load", Phd Thesis, Zhejiang University, 2013.

\section{(C) 2019 Yang et al.}

This is an open access article distributed under the terms of the Creative Commons Attribution 4.0 International Public License (CC-BY 4.0), a copy of which is available at: https://creativecommons.org/licenses/by/4.0/legalcode. This license permits unrestricted use, distribution, and reproduction in any medium, provided the original author and source are credited. 